\title{
Predictors of Acute Postoperative Pain After Elective Surgery
}

Citation for published version (APA):

Sommer, M., de Rijke, M. M., van Kleef, M., Kessels, A. G. H., Peters, M. L., Geurts, J. W., Patijn, J., Gramke, H., \& Marcus, M. A. E. (2010). Predictors of Acute Postoperative Pain After Elective Surgery. Clinical Journal of Pain, 26(2), 87-94. https://doi.org/10.1097/AJP.0b013e3181b43d68

Document status and date:

Published: 01/01/2010

DOI:

10.1097/AJP.0b013e3181b43d68

Document Version:

Publisher's PDF, also known as Version of record

Document license:

Taverne

Please check the document version of this publication:

- A submitted manuscript is the version of the article upon submission and before peer-review. There can be important differences between the submitted version and the official published version of record.

People interested in the research are advised to contact the author for the final version of the publication, or visit the DOI to the publisher's website.

- The final author version and the galley proof are versions of the publication after peer review.

- The final published version features the final layout of the paper including the volume, issue and page numbers.

Link to publication

\footnotetext{
General rights rights.

- You may freely distribute the URL identifying the publication in the public portal. please follow below link for the End User Agreement:

www.umlib.nl/taverne-license

Take down policy

If you believe that this document breaches copyright please contact us at:

repository@maastrichtuniversity.nl

providing details and we will investigate your claim.
}

Copyright and moral rights for the publications made accessible in the public portal are retained by the authors and/or other copyright owners and it is a condition of accessing publications that users recognise and abide by the legal requirements associated with these

- Users may download and print one copy of any publication from the public portal for the purpose of private study or research.

- You may not further distribute the material or use it for any profit-making activity or commercial gain

If the publication is distributed under the terms of Article $25 \mathrm{fa}$ of the Dutch Copyright Act, indicated by the "Taverne" license above, 


\title{
Predictors of Acute Postoperative Pain After Elective Surgery
}

\author{
Michael Sommer, MD,* Janneke M. de Rijke, PhD, ${ }^{*}$ Maarten van Kleef, MD, PhD,* \\ Alfons G. H. Kessels, MD, MSc, † Madelon L. Peters, PhD, $\ddagger$ José W. Geurts, MSc,* \\ Jacob Patijn, MD, * Hans-Fritz Gramke, MD, ${ }^{*}$ and Marco A. E. Marcus, MD, PhD*
}

\begin{abstract}
Objectives: Objectives:Despite efforts to improve acute postoperative pain management, a substantial number of patients still experience moderate to severe pain during the immediate postoperative days. The purpose of the present study was to identify predictors of moderate to severe acute postoperative pain.

Methods: Methods: A total of 1490 patients undergoing heterogeneous surgical procedures recorded their pain 3 times a day on a 100 -mm visual analog scale from the day before the operation until 5 days postoperation. For each postoperative day, pain intensity was classified as moderate when the mean pain score was 41 to $74 \mathrm{~mm}$ and as "severe when the mean pain score was 75 to $100 \mathrm{~mm}$. Using logistic regression analyses, we examined the predictive value of a comprehensive set of preoperative and perioperative variables for moderate to severe pain.
\end{abstract}

Results: Results: The most important predictors seemed to be; preoperative pain, expected pain, surgical fear, and pain catastrophizing.

Discussion: Discussion: Several predictive factors of postoperative pain were identified in this study. These factors could be taken into account in postoperative pain management.

Key Words: pain, predictors, prevalence, postoperative, surgery

(Clin J Pain 2010;26:87-94)

$\mathrm{D}$ espite all research efforts to improve acute postoperative pain management still up to $30 \%$ of operated patients show pain scores higher than 3 on a visual analog scale (VAS) of $10 .{ }^{1-3}$ Acute postoperative pain management is increasingly used as an indicator to judge the quality of intramural health care. The Joint Commission of Healthcare Organization stated that the goal of acute postoperative pain management is to reduce patients' pain to a level VAS $<3$ both at rest and during movement of the patient. Adequate postoperative pain management is not only indispensable for reasons of humanity and patient's comfort, but also there is a strong relationship between effective postoperative pain management and the prevention of acute organ dysfunction., ${ }^{4,5}$ Furthermore, high postoperative pain increases the risk of developing chronic pain. ${ }^{5-7}$

Received for publication April 17, 2008; revised March 4, 2009; accepted March 9, 2009

From the Departments of *Anaesthesiology and Pain Treatment; †Clinical Epidemiology and MTA; and \$Clinical Psychological Science, University Hospital Maastricht, Maastricht, The Netherlands.

Funding Support: The support came from the Pain Management and

Research Centre subsidized by the Ministry of Health, The Netherlands.

Reprints: Michael Sommer, MD, Department of Anaesthesiology, University Hospital Maastricht, PO Box 5800, 6202 AZ Maastricht,

The Netherlands (e-mail: Jose.geurts@mumc.nl).

Copyright (C) 2010 by Lippincott Williams \& Wilkins
Few studies have tried to identify factors that could predict the seriousness of postoperative pain. In a study of 1416 postoperative patients, a relationship between sex, age, preoperative pain, incision size, type of surgery on the 1 side and postoperative pain severity on the other side was identified. ${ }^{8}$ However, pain measurements in this study were restricted to the first 3 postoperative hours. In addition, the outcome measure in this study was defined as a numerical pain rating score above 8 of 10 at least once within the first hour after arrival on the postanesthesia care unit (PACU), which is well above the VAS of 3 mentioned by the Joint Commission of Healthcare Organization.

Other predictor studies in postoperative pain found an association between moderate or severe pain and age ${ }^{9,10}$ or female sex. ${ }^{11}$ However, in these studies the populations were limited to 1 or 2 surgical departments ${ }^{11}$ or an observation period of 24 hours postoperatively. ${ }^{9}$

Psychologic factors have also been proposed to influence postoperative pain. An important determinant of acute postoperative pain intensity seems to be preoperative anxiety. ${ }^{12-14}$ However, because of the small number of predictor studies and the limitations of some of these studies, no definite conclusion can be drawn regarding factors predicting which patient is at risk of moderate or severe postoperative pain. Therefore, we conducted a prospective study to investigate the predictive value of a comprehensive set of both somatic and psychologic factors on the level of postoperative pain.

\section{PATIENTS AND METHODS}

After approval by the institutional ethics committee and informed consent from the patients, consecutive patients, admitted to the ward and scheduled for elective surgery at the University Hospital Maastricht, The Netherlands in the period February 1 till August 30, 2003 were asked to participate in the study. The following surgical departments participated: general, plastic, ear-nose-throat, facio-maxillary, neurology, and thoracic surgery and orthopaedics, ophthalmology, gynaecology, and urology. Excluded were minors less than 18 years, patients with limitations of self-expression, visual dysfunction or Dutch language problems. Patients undergoing emergency surgery, cardiac surgery or cesarean section as well as patients receiving postoperative ventilatory support were also excluded from the study.

\section{Preoperative Assessment, Procedures, and Measurements}

Eligible patients received a letter describing the purpose and methods of the study and a set of questionnaires 1 to 3 weeks preceding the operation. The questionnaires assessed psychologic constructs that were 
deemed relevant in explaining individual differences in the perception of postoperative pain. Previous research has found that pain catastrophizing, defined as the tendency to attach an exaggerated negative meaning to pain, is associated with higher pain intensity and more pain disability in patients with various pain syndromes, and predicts pain intensity after surgery. ${ }^{15}$ We used the pain catastrophizing scale (PCS), which consists of 13 items that can be summed to yield a single pain catastrophizing score. ${ }^{16,17}$ As anxiety was also found to predict pain after surgical procedures in previous studies, $, 8,13,14$ we included both a measure of anxiety as a global personality trait and a more specific measure of surgical anxiety (see below). Anxiety as a global trait was measured using the Behavioral Inhibition Scale (BIS). The BIS consists of 7 items that measure a generally anxious and apprehensive style of reacting to novel and potentially threatening situations. ${ }^{18}$ In addition to these potential vulnerability factors we also included possible protective variables, namely optimism and self-efficacy. Optimism was measured using the Life Orientation Test (LOT). ${ }^{19}$ The LOT consists of 12 items: 4 positively formulated items, 4 negatively formulated items, and 4 filler items. On the basis of summation of the 8 relevant items (after recoding the negative items), a single dispositional optimism score can be obtained. Finally, selfefficacy was measured using the General Self-Efficacy Scale (GSES). The GSES consists of 10 items that measure an individual's belief that he or she has the ability to reach most of his/her life goals. ${ }^{20}$ All items are summed to yield a single score. The PCS, BIS, LOT, and GSES were filled out at home and patients were requested to bring the completed questionnaires to the hospital on the day of admission, generally the day before surgery.

After admission to the surgical ward, a trained research assistant explained the purpose and methods of the study to each eligible patient who was willing to participate. At that moment, sociodemographic variables were recorded such as date of birth, sex, and education and also a questionnaire on surgical fear was filled out. This 10-item questionnaire on surgical fear was adapted from Koivula et al. ${ }^{21}$ Two subscales were derived, based on a principal component analysis of the items: short-term fear and long-term fear. ${ }^{6}$ The short-term fear subscale consisted of 4 items related to the immediated consequences of surgery (eg, fear of pain, anesthetics; Cronbach $\alpha=0.83$ ); the long-term fear subscale consisted of 6 items related to future consequences of the operation (eg, fear of inadequate recovery, financial consequences; Cronbach $\alpha=0.82$ ). Furthermore, pain intensities at rest and while coughing, and expected pain after the operation were scored, using a 100-mm VAS anchored to "no pain" and "worst pain I can imagine."

\section{Postoperative Assessment and Measurements}

Pain intensity at rest and while coughing was scored 1 and 3 hours postoperatively. Additionally, on the day of surgery, pain assessment at the time of going to sleep, approximately $9 \mathrm{PM}$, was done to obtain a third value for the mean pain score. Using a pain diary, the patient scored pain 3 times a day, on days 1 to 4 after the day of surgery. Research assistants visited all patients at least once a day to give assistance when necessary. When patients were physically not able to fill in the diary themselves, researchassistants offered assistance 3 times a day.
The type of anesthesia was not regulated by the study protocol. The choice of technique and agents to be used was left to the individual anesthesiologist and patient. (Agents used for general anesthesia were propofol, etomidate, sevoflurane and desflurane, sufentanil, fentanyl, rocuronium, and vecuronium). Perioperative pain was treated according to the stepwise approach of acute pain treatment described by Rawal. ${ }^{22}$ The anesthetic techniques used during the operation were documented as well as details of analgesia (epidural, spinal, intravenous, oral, etc) administered from 0 to 4 days postsurgery. After the operation, all patients went to the PACU.

Patients who were discharged from hospital within 4 days postoperatively took their diary home and returned it to us in a special prepaid envelope. Contacting patients by phone made it possible to retrieve diaries that had not been returned within 14 days after surgery.

All surgical procedures were categorized in 3 groups (minor, intermediate, and major surgery) according to the anticipated level of postoperative pain. ${ }^{23}$ Subsequently, all surgical procedures were categorized according to the involved 7 anatomic body regions head/neck, upper extremities, thorax, back, upper and lower abdomen, and lower extremities $^{24}$ (Table 1).

According to our preoperative standardized protocol, all patients received paracetamol preemptively. Postoperative pain in the minor operation group was treated with paracetamol $(1000 \mathrm{mg} 4$ times a day combined with nonsteroidal anti-inflammatory drugs) administered by ward nurses. Escape medication in case of moderate or severe pain (VAS $>40$ ) was piritramide intramuscularly. Pain after intermediate operations was treated according to the same protocol combined with a small dose of intravenous piritramide ( 2 to $5 \mathrm{mg}$ ) followed by intramuscular piritramide 10 to $15 \mathrm{mg} 6$ times a day. For major operations, piritramide was prescribed by intermittent intravenous infusion on patient's demand (patient controlled analgesia), according to the protocol. The patient controlled analgesia protocol included 3 levels of piritramide doses $(1.0,1.5$, and $2 \mathrm{mg}$ per bolus, stop interval $5 \mathrm{~min})$. In many cases, the major operations were conducted with a combination of general anesthesia and epidural anesthesia. Postoperatively, pain was treated by a continuous epidural infusion of bupivacaine $0.125 \%$ with sufentanil $0.5 \mu \mathrm{g} / \mathrm{mL}$.

After a PACU observation period of 2 to 4 hours, patients with minor and intermediate operations returned to the surgical ward with nurses acquainted with the postoperative pain protocol. A trained postoperative pain nurse followed patients with major operations at least twice a day during 4 days postoperatively.

\section{Statistical Analyses}

Mean pain VAS scores on the day of the operation and on postoperative days 0 to 4 (POD $1-4$ ) were calculated, using the average of the 3 scores obtained from each individual on each of the days. This assessment per day is of direct clinical relevance in patient management, specifically in decision making regarding discharge and pain treatment.

As the pain diaries were sometimes incomplete, totals could vary from day to day. A mean pain score of higher than $40 \mathrm{~mm}$ on a VAS was regarded as being unacceptable. ${ }^{25-27}$

Missing values in predictor variables were imputed. This was done because of a presumed nonresponse problem 


\begin{tabular}{|c|c|c|}
\hline $\begin{array}{l}\text { Anticipated Pain } \\
\text { Level }\end{array}$ & Anatomic Site & Surgical Procedure \\
\hline \multirow[t]{6}{*}{ Minor } & $\begin{array}{l}\text { Head and neck } \\
\quad \mathrm{N}=295\end{array}$ & $\begin{array}{l}\text { Thyroidectomy, stapedectomy, tympanoplasty, petrosal bone and middle ear surgery, } \\
\text { cochlear implantation, middle ear inspection, middle ear reconstruction, auricle } \\
\text { reconstruction, nasal sinus inspection, endoscopy of pharynx, larynx, bronchus, } \\
\text { intracranial tumour surgery, craniotomy, eye surgery }\end{array}$ \\
\hline & $\begin{array}{l}\text { Upper extremity } \\
\mathrm{N}=10\end{array}$ & Peripheral vascular operations, wound toilet, sutures \\
\hline & $\begin{array}{l}\text { Thorax - noncardiac } \\
\qquad(\mathrm{N}=10)\end{array}$ & Vascular operations, wound toilet \\
\hline & $\begin{array}{l}\text { Lower abdomen/pelvis } \\
\qquad \mathrm{N}=138\end{array}$ & $\begin{array}{l}\text { Vaginal urologic procedures, cervix operation, abortion, hysteroscopy, operations } \\
\text { of male genital, endoscopic urologic interventions for example, transurethral } \\
\text { resection, cystic biopsy, urethra, cystoscopy, plastic skin operations }\end{array}$ \\
\hline & $\begin{array}{l}\text { Lower extremity } \\
\qquad \mathrm{N}=20\end{array}$ & Plastic skin operations, peripheral vascular operations, wound toilet \\
\hline & $\begin{array}{l}\text { Back/Spinal } \\
\quad \mathrm{N}=13\end{array}$ & Urologic neuromodulation, small plastic skin operations, \\
\hline \multirow[t]{8}{*}{ Intermediate } & $\begin{array}{l}\text { Head and neck } \\
\quad \mathrm{N}=85\end{array}$ & $\begin{array}{l}\text { Neck dissection, mouth and throat surgery, laryngectomy, pharynx and larynx } \\
\text { surgery, maxilla and mandibular surgery }\end{array}$ \\
\hline & $\begin{array}{l}\text { Upper extremity } \\
\mathrm{N}=39\end{array}$ & Orthopedic hand and arm surgery \\
\hline & $\begin{array}{l}\text { Thorax - noncardiac } \\
\mathrm{N}=31\end{array}$ & Oncologic and plastic breast surgery \\
\hline & $\begin{array}{l}\text { Upper abdomen } \\
\mathrm{N}=69\end{array}$ & Fundoplication, duodenum surgery, cholecystectomy, nephrectomy \\
\hline & $\begin{array}{l}\text { Lower abdomen/pelvis } \\
\quad \mathrm{N}=195\end{array}$ & $\begin{array}{l}\text { Surgery of vulva, ovary, adnexen, vaginal and abdominal uterusextirpation, } \\
\text { abdominal endometriosis, closure of anus praeter, colorectal surgery, anal surgery, } \\
\text { abdominal vascular surgery, abdominal lipectomy, cystic resection, Ryntshak and } \\
\text { radical prostatectomy }\end{array}$ \\
\hline & $\begin{array}{l}\text { Lower extremity } \\
\quad \mathrm{N}=212\end{array}$ & $\begin{array}{l}\text { Plastic skin operations, orthopedic surgery foot } / \mathrm{knee} / \mathrm{leg} / \mathrm{hip} \text {, amputation, peripheral } \\
\text { vascular surgery }\end{array}$ \\
\hline & $\begin{array}{l}\text { Back/spinal } \\
\quad \mathrm{N}=63\end{array}$ & $\begin{array}{l}\text { Plastic skin operations, spinal cord decompression with hemilaminectomy, } \\
\text { discectomy }\end{array}$ \\
\hline & $\begin{array}{l}>\text { than } 1 \text { site } \\
\mathrm{N}=12\end{array}$ & Plastic breast + abdominal surgery, arm/hand and hip (fractures) \\
\hline \multirow[t]{5}{*}{ Major } & $\begin{array}{l}\text { Upper extremity } \\
\mathrm{N}=23\end{array}$ & Shoulder surgery (endoprothesis), clavicle surgery \\
\hline & $\begin{array}{l}\text { Thorax }- \text { noncardiac } \\
N=10\end{array}$ & Lobectomy \\
\hline & $\begin{array}{l}\text { Upper + lower abdomen } \\
\mathrm{N}=171\end{array}$ & $\begin{array}{l}\text { Hepatectomy, pancreatectomy, combination of different bowel surgery, aortic } \\
\text { surgery, extensive gynecologic surgery, combination of bowel and gynecologic } \\
\text { surgery }\end{array}$ \\
\hline & $\begin{array}{l}\text { Lower extremity } \\
\quad \mathrm{N}=60\end{array}$ & Total knee replacement \\
\hline & $\begin{array}{c}\text { Back/spinal } \\
\mathrm{N}=34\end{array}$ & Spondylodesis, spinal cord tumour resection, untethering \\
\hline
\end{tabular}

TUR indicates transurethral resection.

where the occurrence of missing data is related to the outcome value pain. Patients, who did not fill in all data, may have had severe pain at that point in time or in contrast, no pain at all. Either way this could influence the outcome. Missing predictor values were imputed according to the multiple imputation method described by van Buuren and Rubin. ${ }^{28,29}$ Assuming a Missing At Random mechanism, each missing value can be imputed using a regression model with the other covariates and outcome as predictor. The imputation is a stochastic process as the value is drawn from a density function generated by the regression model. In this way, a complete data set is generated and this process is repeated at least twice. For the present study the imputation procedure was performed 5 times, obtaining 5 complete datasets, with imputed values: short-term fear (n missing $=37 ; 2.5 \%$ ), long-term fear $(\mathrm{n}=36 ; 2.4 \%)$, pain catastrophizing $(\mathrm{n}=51 ; 3.4 \%)$, expected pain $(\mathrm{n}=51 ; 3.4 \%)$, preoperative pain $(\mathrm{n}=8 ; 0.5 \%)$, optimism $(\mathrm{n}=55 ; 3,7 \%)$, self-efficacy $(\mathrm{n}=94,6.3 \%)$, and anxiety disposition $(\mathrm{n}=94 ; 6.3 \%)$. For each of the 5 datasets, which were obtained after multiple imputation, multiple logistic regression analysis was performed to identify the factors that independently predicted the risk of having unacceptable postoperative pain $(\geq 40)$ on the day of surgery and day 1 to 4 after operation. Easily obtainable predictors were included first (Table 3). In the first block, 2 variables related to the surgical procedure were entered: type of surgery (minor, intermediate, major) and anatomic body region. In the second block, the demographic variables age (3 groups: $<45 \mathrm{y}, 45-59 \mathrm{y}$, and $60 \mathrm{y}$ and older ) and sex were entered. Preoperative pain (yes or no VAS $>40$ ), duration of the operation (yes or no $\geq 3 \mathrm{~h}$ ), anesthetic technique (general, loco-regional or general+loco-regional), and 
TABLE 2. Total Patient Characteristics and According to the Number (n) and Proportion (\%) of Patients With a Mean Pain in Rest of $>40$ on a Visual Analog Scale (VAS)

\begin{tabular}{|c|c|c|c|c|c|c|}
\hline & \multirow{2}{*}{ 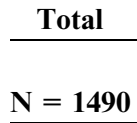 } & \multicolumn{5}{|c|}{ Mean VAS > 40} \\
\hline & & $\begin{array}{c}\text { Operation Day } \\
N=1398\end{array}$ & $\begin{array}{c}\text { POD 1 } \\
N=1300\end{array}$ & $\begin{array}{c}\text { POD 2 } \\
\mathrm{N}=1295\end{array}$ & $\begin{array}{c}\text { POD 3 } \\
\mathbf{N}=1275\end{array}$ & $\begin{array}{c}\text { POD } 4 \\
N=1247\end{array}$ \\
\hline & $\mathrm{N} / \%$ & $\mathrm{~N} / \%$ & $\mathrm{~N} / \%$ & $\mathrm{~N} / \%$ & $\mathrm{~N} / \%$ & $\mathrm{~N} / \%$ \\
\hline \multicolumn{7}{|l|}{ Age } \\
\hline$<45 \mathrm{y}$ & $374 / 25$ & $151 / 42$ & $112 / 35$ & $66 / 21$ & $47 / 15$ & $49 / 16$ \\
\hline $45-59 y$ & $449 / 30$ & $179 / 43$ & $134 / 33$ & $78 / 19$ & $80 / 20$ & $59 / 15$ \\
\hline $60+$ years & $667 / 45$ & $182 / 29$ & $147 / 25$ & $97 / 17$ & $75 / 13$ & $59 / 11$ \\
\hline $\begin{array}{l}\text { mean (y) (SD) } \\
\text { Sex }\end{array}$ & \multirow{2}{*}{\multicolumn{6}{|c|}{ Sex }} \\
\hline $\begin{array}{l}\text { Sex } \\
\text { Male }\end{array}$ & & $193 / 30$ & $145 / 24$ & $93 / 15$ & & \\
\hline Female & $788 / 53$ & $319 / 43$ & $248 / 36$ & $148 / 22$ & $124 / 19$ & $105 / 16$ \\
\hline \multicolumn{7}{|l|}{ Type of anesthesia } \\
\hline General & $1024 / 69$ & $402 / 42$ & $269 / 30$ & $175 / 20$ & $141 / 16$ & $113 / 13$ \\
\hline Locoregional* & $270 / 18$ & $50 / 28$ & $58 / 25$ & $33 / 14$ & $31 / 14$ & $21 / 10$ \\
\hline General + Locoregional $\dagger$ & $196 / 13$ & $60 / 23$ & $66 / 38$ & $33 / 19$ & $30 / 17$ & $33 / 20$ \\
\hline \multicolumn{7}{|l|}{ Type of surgery } \\
\hline Minor & $486 / 33$ & $105 / 23$ & $71 / 16$ & $51 / 12$ & $39 / 9$ & $36 / 9$ \\
\hline Intermediate & $706 / 47$ & $295 / 44$ & $212 / 35$ & $122 / 20$ & $104 / 17$ & $75 / 13$ \\
\hline Major & $298 / 20$ & $112 / 42$ & $110 / 43$ & $68 / 27$ & $59 / 24$ & $56 / 23$ \\
\hline \multicolumn{7}{|l|}{ ASA score } \\
\hline 1 & $538 / 36$ & $206 / 40$ & $145 / 31$ & $82 / 17$ & $72 / 15$ & $57 / 13$ \\
\hline 2 & $684 / 46$ & $221 / 35$ & $186 / 30$ & $117 / 19$ & $91 / 15$ & $76 / 13$ \\
\hline $3-4$ & $268 / 18$ & $85 / 36$ & $62 / 29$ & $42 / 19$ & $39 / 18$ & $34 / 17$ \\
\hline \multicolumn{7}{|l|}{ Duration of operation } \\
\hline$<3 \mathrm{~h}$ & $1045 / 70$ & $240 / 27$ & $243 / 26$ & $143 / 16$ & $122 / 13$ & $104 / 12$ \\
\hline $3 \mathrm{~h}$ or more & $445 / 30$ & $150 / 39$ & $150 / 39$ & $98 / 25$ & $80 / 21$ & $63 / 16$ \\
\hline Total & $1490 / 100$ & $512 / 34$ & $393 / 30$ & $241 / 19$ & $202 / 16$ & $167 / 14$ \\
\hline
\end{tabular}

*40 patients in this group received "peripheral blocks."

+5 patients in this group received general anesthesia + "peripheral block."

ASA indicates American Society of Anesthesiologists; POD, postoperative day.

American Society of Anesthesiologists grade were entered in the third block using a forward stepwise procedure. The psychologic parameters (expected pain, pain catastrophizing, self-efficacy, anxiety disposition, shortterm fear, long-term fear, and optimism) were examined in the final step, also with a forward stepwise procedure. To simplify the prediction algorithm so as to make it more practical and manageable for the physician, psychologic variables were dichotomized by median split. In all the steps, a $P$ value of 0.05 was used for keeping variables in the model. Next, the results (estimates of coefficients and standard errors) of the identical analyses on each of the 5 datasets were combined to calculate overall estimates, standard errors and $95 \%$ confidence intervals. ${ }^{28,29}$ Predictors were included in the final model if they were significant predictors in more than 3 datasets. The model's ability to discriminate between patients with and without unacceptable postoperative pain was estimated by the area under the receiver operant curve for the successive blocks.

Missing values in outcome measures (pain scores) were not imputed. However, these missing data could also be subject to selection processes. Therefore, we investigated with logistic regression analyses whether these missing outcomes could be predicted with available covariates (age, type of operation, sex, etc). The results revealed some significant relationships and were used to calculate a $\mathrm{P}$ weight factor for each case. Analyses were performed with STATA (version 8) and SPSS (version 12).

\section{RESULTS}

Data on a total of 1490 patients were studied. Patient characteristics are presented in Table 2 . Slightly fewer male patients participated in this study than female patients $(47 \%$ vs. $53 \%)$. Forty-five percent of the patients were 60 years of age or older. In all, $1663(85 \%)$ of 1975 eligible patients consented to participate. Out of that, $140(8 \%)$ patients dropped out for a variety of reasons: postoperative ventilatory support $(\mathrm{n}=50)$, too burdensome for the patient $(n=32)$, complications followed by a new operation $(n=14)$, and other diverse reasons $(n=44)$. The questionnaires from $33(2 \%)$ patients were not assessable because too many data were missing, leaving 1490 evaluated patients. Distribution of age and sex among the nonresponders was not significantly different from the participating patients.

We performed a logistic regression analysis for the risk of moderate or severe postoperative pain (ie, pain $>40$ on a $100-$ mm VAS) on the day of operation and day 1 to 4 (Table 3). If the surgical procedure was categorized as intermediate with respect to the anticipated postoperative pain the risk of higher VAS was increased on day 0 and 1 . If the operation was categorized as being major, the risk was increased on day 1 and 2 .

With respect to the anatomic site, the head and neck procedures functioned as reference $(=1.0)$. The risk of pain $>40$ on a $100-$ mm VAS was statistically higher after upper-extremity operations on day 1 but not on the other days. After leg or hip surgery, the risk of moderate or severe 


\begin{tabular}{|c|c|c|c|c|c|c|c|c|c|c|}
\hline \multirow{2}{*}{$\begin{array}{l}\text { Independent Variable } \\
N \\
\end{array}$} & \multicolumn{2}{|c|}{$\begin{array}{c}\text { Day of Operation } \\
\mathbf{N}=1398 \\
\end{array}$} & \multicolumn{2}{|c|}{$\begin{array}{c}\text { POD 1 } \\
\mathbf{N}=1300\end{array}$} & \multicolumn{2}{|c|}{$\begin{array}{c}\text { POD 2 } \\
\mathbf{N}=1307 \\
\end{array}$} & \multicolumn{2}{|c|}{$\begin{array}{c}\text { POD 3 } \\
\mathbf{N}=1285 \\
\end{array}$} & \multicolumn{2}{|c|}{$\begin{array}{c}\text { POD } 4 \\
\mathrm{~N}=1275 \\
\end{array}$} \\
\hline & OR $(95 \%$ CI) & AUC & OR $(95 \%$ CI $)$ & AUC & OR $(95 \%$ CI $)$ & $\mathbf{A U C}$ & OR $(95 \%$ CI $)$ & AUC & OR $(95 \%$ CI) & AUC \\
\hline Step 1 & & 0.62 & & 0.66 & & 0.65 & & 0.65 & & 0.65 \\
\hline \multicolumn{11}{|l|}{ Anticipated pain level } \\
\hline Intermediate versus minor & $1.93(1.38-2.71)$ & & $1.54(1.05-2.25)$ & & $1.13(0.70-1.83)$ & & $1.32(0.78-2.23)$ & & $0.99(0.52-1.87)$ & \\
\hline Major versus minor & $1.57(0.91-2.72)$ & & $2.04(1.15-3.60)$ & & $2.31(1.20-4.49)$ & & $1.92(0.92-4.03)$ & & $1.54(0.86-3.52)$ & \\
\hline \multicolumn{11}{|l|}{ Anatomic site } \\
\hline Head/neck (reference) & 1.0 & & 1.0 & & 1.0 & & 1.0 & & 1.0 & \\
\hline Upper extremities & $1.19(0.64-2.19)$ & & $2.01(1.04-3.91)$ & & $1.66(0.76-3.62)$ & & $2.09(0.95-4.63)$ & & $1.80(0.74-4.38)$ & \\
\hline Thorax/noncardiac & $1.84(0.95-3.55)$ & & $1.15(0.53-2.48)$ & & $1.53(0.67-3.50)$ & & $1.35(0.52-3.50)$ & & $0.96(0.31-3.05)$ & \\
\hline Upper abdomen & $1.27(0.68-2.35)$ & & $1.66(0.85-3.25)$ & & $1.46(0.64-3.32)$ & & $1.75(0.74-4.15)$ & & $1.11(0.40-3.10)$ & \\
\hline Lower Abdomen/pelvis & $1.37(0.94-2.01)$ & & $1.33(0.87-2.04)$ & & $1.16(067-1.98)$ & & $1.28(0.71-2.30)$ & & $0.83(0.42-1.65)$ & \\
\hline Abdominal U + L & $1.92(0.98-3.76)$ & & $1.24(0.62-2.46)$ & & $0.47(0.20-1.12)$ & & $0.95(0.38-2.41)$ & & $1.02(0.38-2.74)$ & \\
\hline Lower extremities & $1.63(1.01-2.62)$ & & $1.66(0.95-2.93)$ & & $1.57(0.81-3.02)$ & & $1.13(0.54-2.37)$ & & $1.08(0.47-2.49)$ & \\
\hline Back & $1.55(0.88-2.73)$ & & $1.80(0.98-3.29)$ & & $1.90(0.95-3.67)$ & & $1.74(0.80-3.75)$ & & $0.98(0.40-2.40)$ & \\
\hline Step 2 & & 0.66 & & 0.68 & & 0.66 & & 0.66 & & 0.65 \\
\hline \multicolumn{11}{|l|}{ Age } \\
\hline$<45 \mathrm{y}$ versus $60+\mathrm{y}$ & $1.27(0.94-1.71)$ & & $1.26(0.91-1.73)$ & & $0.98(0.67-1.46)$ & & $0.94(0.61-1.44)$ & & $1.40(0.88-2.18)$ & \\
\hline $45-59$ y versus $60+y$ & $1.40(1.06-1.86)$ & & $1.31(0.96-1.77)$ & & $0.98(0.68-1.41)$ & & $1.52(1.03-2.24)$ & & $1.37(0.89-2.11)$ & \\
\hline \multicolumn{11}{|l|}{ Sex } \\
\hline Female versus male & $0.74(0.57-0.95)$ & & $0.77(0.59-1.01)$ & & $0.95(0.69-1.31)$ & & $0.89(0.63-1.26)$ & & $0.86(0.59-1.24)$ & \\
\hline Step 3 & & 0.71 & & 0.72 & & 0.73 & & 0.74 & & 0.76 \\
\hline \multicolumn{11}{|l|}{ Preoperative pain } \\
\hline Yes versus no & $2.19(1.55-3.09)$ & & $2.42(1.68-3.47)$ & & $2.55(1.72-3.77)$ & & $3.43(2.27-5.18)$ & & $3.88(2.48-6.08)$ & \\
\hline \multicolumn{11}{|l|}{ Anesthetic technique } \\
\hline General $(\mathrm{G})$ versus $\mathrm{G}+\mathrm{C}$ & $2.63(1.76-3.94)$ & & $1.42(0.94-2.15)$ & & $1.87(1.10-3.17)$ & & $1.24(0.73-2.11)$ & & $1.59(0.85-3.00)$ & \\
\hline Central(C) versus $\mathrm{G}+\mathrm{C}$ & $0.90(0.53-1.49)$ & & $1.56(0.94-2.60)$ & & $1.67(0.85-3.31)$ & & $1.16(0.58-2.33)$ & & $2.31(1.12-4.77)$ & \\
\hline Step 4 & & 0.74 & & 0.74 & & 0.77 & & 0.77 & & 0.78 \\
\hline \multicolumn{11}{|l|}{ Expected pain $>40$} \\
\hline Yes versus no & 2.15 (1.64- 2.83) & & $2.12(1.61-2.78)$ & & $2.12(1.51-2.98)$ & & $1.90(1.33-2.73)$ & & $2.30(1.55-3.41)$ & \\
\hline \multicolumn{11}{|l|}{ Short-term fear } \\
\hline High $(\geq 13)$ versus low $(<13)$ & $1.42(1.07-1.90)$ & & $1.19(0.87-1.62)$ & & $1.36(0.94-1.96)$ & & $1.01(0.69-1.49)$ & & $1.17(0.76-1.81)$ & \\
\hline \multicolumn{11}{|l|}{ Long-term fear } \\
\hline High $(\geq 10)$ versus low $(<10)$ & $1.14(0.86-1.53)$ & & $1.43(1.06-1.93)$ & & $1.58(1.10-2.28)$ & & $1.49(1.00-2.21)$ & & $1.27(0.83-1.95)$ & \\
\hline \multicolumn{11}{|l|}{ BIS } \\
\hline High $(\geq 20)$ vs. low $(<20)$ & $0.75(0.58-0.97)$ & & $1.04(0.79-1.73)$ & & $0.92(0.21-3.98)$ & & $0.84(0.59-1.19)$ & & $0.88(0.53-1.14)$ & \\
\hline \multicolumn{11}{|l|}{ Pain catastrophizing } \\
\hline \multirow{2}{*}{\multicolumn{11}{|c|}{ GSES }} \\
\hline & & & & & & & & & & \\
\hline High versus low & $1.01(0.78-1.31)$ & & $0.91(0.71-1.18)$ & & $0.75(0.55-1.03)$ & & $0.75(0.53-1.06)$ & & $0.69(0.47-0.99)$ & \\
\hline $\begin{array}{l}\text { Bold Indicates significane ( } P \text { value } \\
\text { Step } 1 \text { and } 2 \text { used a forced entry proced } \\
\text { odds ratio and } 95 \% \text { confidence interva } \\
\text { BIS indicates Behavioral Inhibition }\end{array}$ & $\begin{array}{l}\text {. } \\
\text { whereas in step } 3 \mathrm{a} \\
\text { all variables in the }\end{array}$ & $\begin{array}{l}\text { only si } \\
1 \text { mode }\end{array}$ & $\begin{array}{l}\text { ant variables enter } \\
\text { tabulated. }\end{array}$ & mode & cedure forward). T & eas un & e receiver operant & es $(A$ & or each step are pres & ted and \\
\hline
\end{tabular}


pain was higher on the operation day. Age as a risk factor played only a role in the group 45 to 59 versus 60 years on day 0 and 3 . The patients of the former group had a significant higher risk of pain $>40 \mathrm{~mm}$ on those days. Female sex protected against pain on day 0. Preexisting pain increased the risk of postoperative pain significantly on all days.

The anesthetic technique played a role when general anesthesia was compared with general plus regional anesthesia or regional anesthesia alone. The odds ratio indicates that the risk of pain $>40 \mathrm{~mm}$ is significantly higher in patients receiving general anesthesia only immediately postoperative and on POD 2.

\section{Psychologic Predictors}

Expected pain $>40 \mathrm{~mm}$ increased the risk of postoperative pain significantly on all PODs. A higher shortterm fear score increased the risk of pain $>40 \mathrm{~mm}$ on day 0 . A higher long-term fear score increased the risk of pain on day 1 to $3 .^{6}$ Patients scoring high on the PCS had a significantly higher risk of having pain $>40 \mathrm{~mm}$ on day 2 to 4 .

Generalized self-efficacy seemed to decrease the risk of postoperative pain, however, this only reached significance on POD 4. Unexpectedly, we also found anxious temperament decreased the risk of postoperative pain, but this only reached significance on the day of the operation.

\section{DISCUSSION}

As far as we know, no other study on the prediction of acute postoperative pain has investigated demographic, somatic, and psychologic variables prospectively in so many patients. We followed a total of 1490 patients undergoing various types of surgical interventions 1 day before and 4 days after the operation to find predictors of immediate postoperative pain.

The strongest predictors of moderate or intense postoperative pain in our study were preexisting pain and expected pain $>40$ on a $100-$ mm VAS. Both parameters were statistically significant on all 5 days. Other predictors were pain catastrophizing that was statistically significant from day 2 until the end of our study and long-term fear, which was statistically significant on day 1 to 3 . All other items either showed statistical significance incidentally but not during a longer period of time or showed no significance at all.

The age group 45 to 60 years had significantly more postoperative pain on the day of operation and on POD 3 compared with the group $65+$. In other studies, younger age was found to be correlated with more postoperative pain. Macintyre and Jarvis ${ }^{9}$ analyzed data retrospectively from 1000 patients in the first 24 hours postoperatively after different kinds of surgery. Patients from 15 to 39 years of age had more pain than patients of 61 to 69 years old. The authors argued that pharmacokinetic and pharmacodynamic factors play a role in a different analgesic demand of the different age groups. Decrease in volume distribution and clearance of morphine and decrease in plasma albumin would be responsible for diminished morphine requirements in older people. However, this study used retrospective analysis of the first 24 hours of the postoperative period. In our data, it is the middle-aged group of patients who have higher pain scores. Patients older than 65 years and younger than 40 years have less pain than the group 41 to 64 years of age. Pharmacokinetics can hardly play a role in the middle-aged group when on the other hand the youngest patients and the $65+$ group had comparable VAS. One would expect the 40 to 59 years old to have the same volume distribution, morphine clearance, and plasma albumin levels as the group 18 to 39 years old. A study measuring the plasma levels of analgesics in different age groups could answer this pharmacokinetic question.

Another indicator was "pain before the operation." We found that the risk of moderate or severe pain after surgery increased significantly if patients suffered from pain before the operation compared with those who did not have preexisting pain. This is in accordance with the literature. ${ }^{8,10}$ The basic principal of preoperative pain to influence postoperative pain is not clear. A possible mechanism could be neuroplastic changes in the spinal cord due to chronic noxious input. ${ }^{8}$ However, this is a hypothesis that is difficult to prove. A limitation of our study is that we have no information about the duration of preoperative pain before operation. Neither do we have information about the preoperative long-term application of coanalgesics like antiepileptics or antidepressives, which could influence the outcome. As far as we know no other study on the relationship between the duration of preoperative and postoperative pain is performed. More research is necessary to disclose the effect of long lasting preoperative pain and chronic use of coanalgesics on postoperative pain. Together with "expected pain," these 2 items were strong predictors of increased postoperative pain on all 5 days.

\section{Factors due to the Operation}

After upper extremity operations, there is an increased risk of postoperative pain on day 1 . Most of the patients with upper extremity procedures received single shot regional anesthesia with or without general anesthesia. After 12 hours or less, the local anesthetics are metabolized and pain arises often between $2 \mathrm{AM}$ and $4 \mathrm{AM}$. Most of these procedures in our hospital are performed in a 24-hour setting: the patient will leave the hospital the morning after the operation. A continuous technique is therefore not desirable as complete neurologic function at discharge is required. Probably systemic analgesics were started too late to prevent pain.

After hip surgery or leg surgery, the risk of moderate or severe pain was increased on day 0 . Most of these procedures in our hospital are performed under spinal anesthesia. Probably, patients went back to the ward before systemic analgesic treatment was well adjusted and sensory motor function was restored completely.

\section{Psychologic Parameters}

Patients expecting moderate to severe postoperative pain and patients who held catastrophizing cognitions about the meaning of pain had an increased risk of experiencing postoperative pain $>40 \mathrm{~mm}$ on the VAS. Our finding that preoperative pain catastrophizing is a risk factor for increased levels of postoperative pain converges with the findings from other studies, respectively in pain after abdominal surgery, anterior cruciate ligament repair and cesarean section. ${ }^{30-32}$ These studies also indicated that patients who held catastrophizing cognitions about pain before the operation had an increased risk of higher levels of postoperative pain, and in addition the duration of moderate to severe pain was more prolonged. ${ }^{30}$ Interestingly, 
our finding that pain catastrophizing becomes more important in the latter postoperative days [from the second day postoperation until the fourth (and last) day of observation] coincides with the results from Strulov et $\mathrm{al}^{32}$ that pain catastrophizing predicted pain on the second postoperative day but not on the first. Pavlin et $\mathrm{al}^{30}$ reported an association between pain catastrophizing and pain on the PACU and on day 7 after the operation but not 24 and 48 hours after the operation. They speculated that during the first day(s) on the ward, pain was most severe and patients engaged in limited physical activity, possibly obscuring the relationship between catastrophizing and pain. When patients become more active, the influence of catastrophizing may become more apparent.

Another psychologic factor that influenced postoperative pain was surgical fear. Interestingly, we found a differential effect of fear for the immediate consequences of the operation and fear for the longer-term consequences. Shortterm fear only predicted postoperative pain on the first day, whereas on later days (POD 1-3) it was long-term fear that became significantly associated with an increased risk of more postoperative pain. Moreover, in an earlier publication on the long-term outcome of surgical intervention we also found that it was long-term and not short-term fear that was associated with more pain at 6 months followup. ${ }^{6}$ We may speculate that being afraid of the operation itself and the procedures surrounding it (eg, anesthesia) may quickly wane once the procedure is over and patients realize that nothing serious has happened. However, the long-term consequences like delayed recovery are less tangible and less readily disconfirmed, and may thus influence patients' experiences for a longer time. Previous studies that have looked at the role of preoperative fear as predictor of postoperative pain have not made this distinction, but more generally looked at state and trait anxiety.., 13 Our study demonstrates that it may be worthwhile to look at the content of fear in more detail, as different fears may lead to different outcomes. Moreover, in our study, trait anxiety as measured using BIS was not related to postoperative pain.

The question arises as to whether these predictors can contribute to a better clinical outcome and in which way. With respect to presurgical psychoeducational intervention, a meta-analysis of Johnston and Vogele ${ }^{33}$ in the early 1990 s demonstrated a beneficial effect of all forms of educational preparation but information about the surgical procedure and behavioral instructions provided the greatest benefit in recovery. For spinal pain, patients preoperative relaxation led to a reduced pain medication use and length of hospital stay. ${ }^{34}$ It would be interesting to investigate whether patients with psychologic risk factors could improve after a presurgical psychoeducational intervention. Another interesting question is how to influence anxiety pharmacologically. The antiepileptic drug gabapentin, for example, is proven to be anxiolytic. In 2005, Menigaux and colleagues investigated the effect of gabapentin in knee surgery. ${ }^{35}$ They found that patients undergoing arthroscopic anterior cruciate ligament repair who received $1200 \mathrm{mg}$ of gabapentin as premedication had reduced preoperative anxiety, postoperative VAS scores and therefore morphine requirements, and improved early knee mobilization compared with the patients in the placebo group. ${ }^{36}$ Whether this is a pure anxiolytic effect or an antinociceptive action of gabapentin is difficult to say. At least antinociceptive mechanisms of this drug are known and calcium channel modulation is suspected to be the underlying mechanism of analgesia. $^{37}$

In summary, these are data from a large cohort with only few missing data, and a 4-day follow-up to predict which patients are at risk for acute severe postoperative pain. As strong predictors of postoperative pain after surgery we found: preoperative pain, expected pain above $40 \mathrm{~mm}$ on a $100-\mathrm{mm}$ VAS, long-term fear, and pain catastrophizing. More research is necessary to evaluate the effect of preoperative anxiolytics, patient education, and length of preoperative pain on postoperative pain.

\section{REFERENCES}

1. Botti M, Bucknall T, Manias E. The problem of postoperative pain: issues for future research. Int J Nurs Pract. 2004;10: 257-263.

2. Sauaia A, Min SJ, Leber C, et al. Postoperative pain management in elderly patients: correlation between adherence to treatment guidelines and patient satisfaction. J Am Geriatr Soc. 2005;53:274-282

3. Warfield CA, Kahn CH. Acute pain management. Programs in US hospitals and experiences and attitudes among US adults. Anesthesiology. 1995;83:1090-1094.

4. Joshi GP, Ogunnaike BO. Consequences of inadequate postoperative pain relief and chronic persistent postoperative pain. Anesthesiol Clin North Am. 2005;23:21-36.

5. Gagliese L, Katz J. Age differences in postoperative pain are scale dependent: a comparison of measures of pain intensity and quality in younger and older surgical patients. Pain. 2003;103:11-20.

6. Peters ML, Sommer M, de Rijke JM, et al. Somatic and psychologic predictors of long-term unfavorable outcome after surgical intervention. Ann Surg. 2007;245:487-494.

7. Perkins FM, Kehlet H. Chronic pain as an outcome of surgery. A review of predictive factors. Anesthesiology. 2000;93 $1123-1133$

8. Kalkman CJ, Visser K, Moen J, et al. Preoperative prediction of severe postoperative pain. Pain 2003;105:415-423.

9. Macintyre PE, Jarvis DA. Age is the best predictor of postoperative morphine requirements. Pain. 1996;64:357-364.

10. Thomas T, Robinson C, Champion D, et al. Prediction and assessment of the severity of post-operative pain and of satisfaction with management. Pain. 1998;75:177-185.

11. Uchiyama K, Kawai M, Tani M, et al. Gender differences in postoperative pain after laparoscopic cholecystectomy. Surg Endosc. 2006;20:448-451.

12. Croog SH, Baume RM, Nalbandian J. Pre-surgery psychological characteristics, pain response, and activities impairment in female patients with repeated periodontal surgery. $J$ Psychosom Res. 1995;39:39-51.

13. Munafo MR, Stevenson J. Anxiety and surgical recovery. Reinterpreting the literature. $J$ Psychosom Res. 2001;51: 589-596.

14. Caumo W, Schmidt AP, Schneider CN, et al. Preoperative predictors of moderate to intense acute postoperative pain in patients undergoing abdominal surgery. Acta Anaesthesiol Scand. 2002; 46:1265-1271.

15. Sullivan MJ, Thorn B, Haythornthwaite JA, et al. Theoretical perspectives on the relation between catastrophizing and pain. Clin J Pain. 2001;17:52-64.

16. Sullivan MJ, Stanish W, Waite H, et al. Catastrophizing, pain, and disability in patients with soft-tissue injuries. Pain. 1998;77:253-260.

17. Van Damme S, Crombez G, Bijttebier P, et al. A confirmatory factor analysis of the Pain Catastrophizing Scale: invariant factor structure across clinical and non-clinical populations. Pain. 2002;96:319-324.

18. Carver CS, White TL. Behavioral inhibition, behavioral activation, and affective responses to impending reward and 
punishment: The BIS/BAS Scales. J Pers Soc Psychol. 1994;67:319-333.

19. Scheier MF, Carver CS, Bridges MW. Distinguishing optimism from neuroticism (and trait anxiety, self-mastery, and selfesteem): a reevaluation of the Life Orientation Test. J Pers Soc Psychol. 1994;67:1063-1078.

20. Jerusalem MS. Self-efficacy as a resource factor in stress appraisal processes. In: Schwarzer R, ed. Self-effcacy: Thought Control of Action. Washington DC, USA: Hemisphere; 1994:195-213.

21. Koivula M, Tarkka MT, Tarkka M, et al. Fear and anxiety in patients at different time-points in the coronary artery bypass process. Int J Nurs Stud. 2002;39:811-822.

22. Rawal N. Postoperative pain and its management. In: Rawal $\mathrm{N}$, ed. Management of Acute and Chronic Pain. London: BMJ Books; 1989.

23. Sommer M, de Rijke JM, van Kleef M, et al. The prevalence of postoperative pain in a sample of 1490 surgical inpatients. Eur J Anaesthesiol. 2008;25:267-274,

24. Rawal N. Postoperative pain and its management. Ann Acad Med. Singapore. 1994;23:56-64.

25. Collins SL, Moore RA, McQuay HJ. The visual analogue pain intensity scale: what is moderate pain in millimetres? Pain. 1997;72:95-97.

26. Dolin SJ, Cashman JN, Bland JM. Effectiveness of acute postoperative pain management: I. Evidence from published data. Br J Anaesth. 2002;89:409-423.

27. Jensen MP, Chen C, Brugger AM. Interpretation of visual analog scale ratings and change scores: a reanalysis of two clinical trials of postoperative pain. J Pain. 2003;4:407-414.
28. van Buuren S, Boshuizen HC, Knook DL. Multiple imputation of missing blood pressure covariates in survival analysis. Stat Med. 1999;18:681-694.

29. Rubin DB, Schenker N. Multiple imputation in health-care databases: an overview and some applications. Stat Med. 1991;10:585-598.

30. Pavlin DJ, Sullivan MJ, Freund PR, et al. Catastrophizing: a risk factor for postsurgical pain. Clin J Pain. 2005;21:83-90.

31. Granot M, Ferber SG. The roles of pain catastrophizing and anxiety in the prediction of postoperative pain intensity: a prospective study. Clin J Pain. 2005;21:439-445.

32. Strulov L, Zimmer EZ, Granot M, et al. Pain catastrophizing, response to experimental heat stimuli, and post-cesarean section pain. J Pain. 2007;8:273-279.

33. Johnston M, Vogele C. Benefits of psychological preparation for surgery: a metaanalysis. Ann Behav Med. 1993;15:245-256.

34. Lawlis GF, Selby D, Hinnant D, et al. Reduction of postoperative pain parameters by presurgical relaxation instructions for spinal pain patients. Spine. 1985;10:649-645.

35. Pollak MH, Matthews J, Scott EL. Gabapentin as a potential Treatment for anxiety disorders. Am J Psychiatry. 1998; 155:992-993.

36. Menigaux C, Adam F, Guignard B, et al. Preoperative gabapentin decreases anxiety and improves early functional recovery from knee surgery. Anesth Analg. 2005;100: 1394-1399.

37. Fink K, Dooley DJ, Meder WP, et al. Inhibition of neuronal $\mathrm{Ca}(2+)$ influx by gabapentin and pregabalin in the human neocortex. Neuropharmacology. 2002;42:229-236. 